\title{
"FILO DI LUCE", WORKSHOP EXPERIENCE FOR FASHION AND PRODUCT DESIGNERS DIFFERENT APPROACH ANALYSIS RELATED TO AN INNOVATIVE TEXTILE MATERIAL APPLICATION
}

\author{
Dastoli, C', 2, Santi, R², Piselli, A ${ }^{1,2}$, Soldati, MG'1, Del Curto, B ${ }^{1,2}$ \\ ${ }^{1}$ Politecnico di Milano, Milan (ITALY) \\ ${ }^{2}$ National Interuniversity Consortium of Materials Science and Technology (INSTM), \\ Florence (ITALY)
}

\begin{abstract}
Project-based learning (PBL) is a powerful method to teach designers intuitive and durable knowledge about materials. By experimenting and experiencing materials, participants get a prospective on the properties of the materials they use and are able to learn which possibilities are given by them. Having an up-dated knowledge of materials, from technical and engineering properties to expressive-sensorial perceptions is essential for designers to produce an aware design and exploit the potentials and limits of materials. In this perspective, the educational experience "Filo di Luce" ("Light Fiber") focused the attention on the application of Dreamlux, a patented textile product with illuminated fibers, in design concepts. The full immersion experience was dedicated to students and postgraduates of Product and Fashion Design courses at the School of Design of the Politecnico di Milano. The project brief for product and fashion designers concerned two different topics, as the final application field requires different needs. Product design teaching section aimed to improve participants skills in recognizing a textile material as an essential component of a three-dimensional product. On the other hand, the full immersion method gave to fashion designers the possibility of acquiring technical capabilities when handling a non-conventional fabric. The involvement of participants with diversified academic backgrounds allows to analyse their design method approaches relating the textile material application.
\end{abstract}

Keywords: design methodology, design approach, materials technology, educational experience, participatory design

\section{INTRODUCTION}

The technological advancement of materials and improvements in manufacturing technologies have been essential for product development and have affected designers' decisions [1]. The morphological character of materials, as expressive as they are functional and structural, leads to the proposition of new forms and an experimental approach toward design [2]. At the Design School of Politecnico di Milano the methodology for teaching materials science through merges lectures has become embedded in design classes during both bachelor and master degrees programs [3]. The Design School also organizes short-time educational experiences, or full immersions, in which a project-based learning approach (PBL) allows to enhance students' motivation in materials knowledge and application. PBL methodology refers to design projects which are used as vehicles to motivate and integrate learning [4]. The added values in PBL approach application are due to the fact that students participate actively in the learning process, by improving retention, student satisfaction and diversity. Moreover, PBL has evolved over the years from "made up" projects to industry-sponsored projects where companies provide "real" problems, along with expertise and financial support [5].

Materials provide technical functionality and create product personality, confer structure and value to the final design [6][7], shape positive user experiences. Thus, competences in materials selection, aesthetics of materials and their role in the design process, can lead to new creative opportunities for designers [1]. In this theoretical scenario, the design approach from the project brief to the development of the final product shows different characteristics, linked to the cultural background as well as to the design field in which the designer grew up and works. Despite design field involves very diversified design areas, it is possible to find equivalences in the design process applied when designers approach a new project [8]. Starting from a common knowledge of the design process in project development, it is possible to discern modalities through which the design process is applied, as it differs in tools and methods application according to the specific design area. 
This paper explores the comparison between different design approaches in the design process for a new textile material application through the short-time practical experience "Filo di Luce", conducted in collaboration with the company Samsara srl. Different approaches derived from different academic realities, as the educational experience was dedicated to students and postgraduates of Product and Fashion Design courses at the School of Design of Politecnico di Milano. The company provided the Dreamlux textile material and gave participants the possibility to exchange views, directly and openly with the company CEO.

\section{2 "FILO DI LUCE", TOOLS AND METHODS}

The PBL methodology led to the organization of the "Filo di Luce" in order to inspire innovative application of Dreamlux, a textile product patented, manufactured and distributed by the company Samsara srl [9]. The company provided participants different typologies of Dreamlux material allowing them to handle it and use it for concepts and outfits development.

\subsection{Material sample: Dreamlux, directions for use}

Dreamlux is an innovative fabric which comprises light guiding fibers made by a central core capable of transmitting the light, and by an external sheath that presents a refraction index allowing the transmitted light to partially escape from the fiber. A light source supplied by an electric battery allows the fabric to become bright, and due to fibers brittleness, freehand drawings by scratching and rubbing fibers are possible to obtain (Fig.1). Fibers light and fabrics are available in several colors and typologies, allowing to achieve numerous combinations and to fuel designers' creativity.
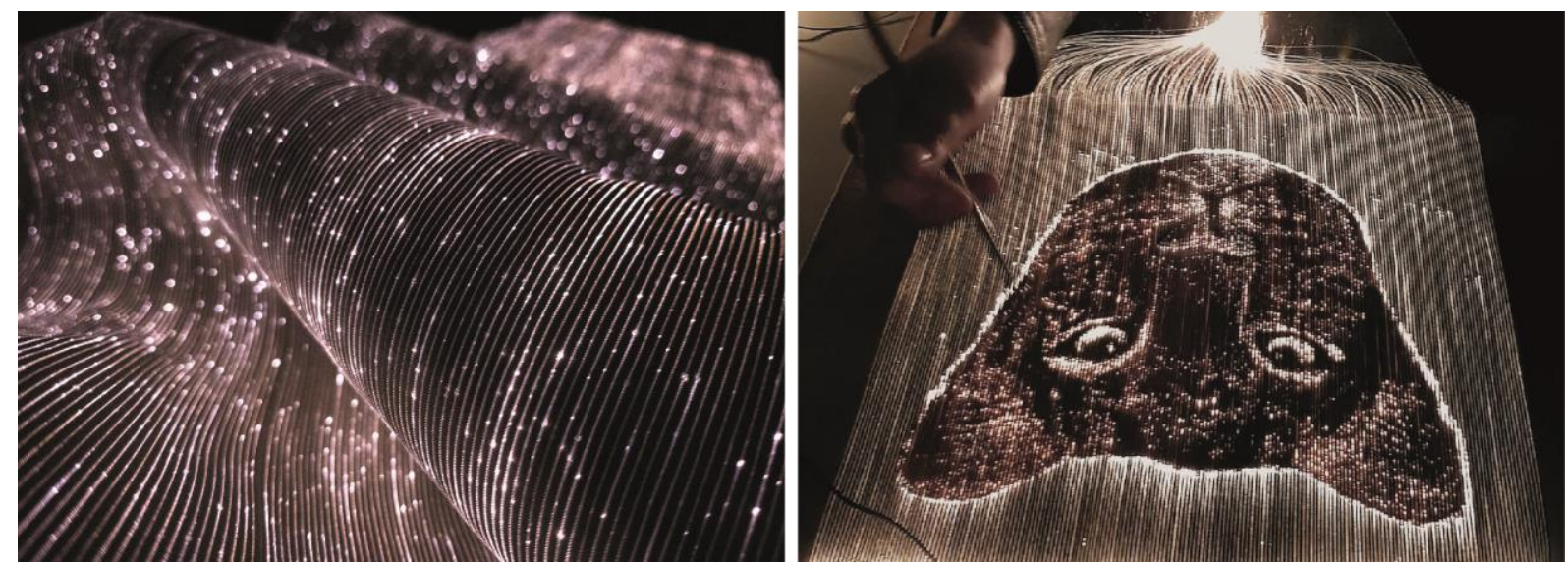

Fig 1. Details of Dreamlux fabric when fibres are brightening (left picture) and fabric superficial modification by fibres manual scratching (right picture)

Despite having optical fibres sewn into the fabric can play a fundamental role in final designers' creative expressiveness, managing Dreamlux can present critical issues related to the textile technological configuration, as brittleness and fibers positioning place constraints in cutting, sewing and shaping the material.

\subsection{Educational experience: brief and structure}

The workshop experience for product and fashion designers concerned two different topics, as the final application field requires different needs. Thus, product designers had to develop concepts relating outdoor furnishing complements while fashion designers were asked to design urban clothing. All participants attended the launch presentation, then full immersion modality was diversified according to the design section, as time and tools available did not permit to product designers to build a prototype of the final product, while was possible for fashion designers to have it. Product designers' workshop started almost one month after the brief was launched, ensuring them the time to set up the possible moodboard and preliminary concepts to be taken forward over the four days workshop lasting. Fashion designers started immediately to present moodboard, conceptboard and technical drawings till the creation of final products, through a series of established review sections. Table 1 resumes the educational experience main organization, while the detailed workshop development for Product and Fashion Design sections is explained in the following paragraphs. 
Table 1. Educational experience brief and timetable for Product and Fashion Design sections.

\begin{tabular}{l|c|c|c|c}
\hline \hline Design & $\begin{array}{c}\text { Workshop } \\
\text { Brief }\end{array}$ & 26 June 2017 & $\begin{array}{c}27 \text { June }-17 \\
\text { July } 2017 \\
\text { Preliminary } \\
\text { activity }\end{array}$ & $\begin{array}{c}18-21 \text { July } \\
2017 \\
\text { Full Immersion }\end{array}$ \\
\hline $\begin{array}{l}\text { Product } \\
\text { Design }\end{array}$ & $\begin{array}{c}\text { Outdoor } \\
\text { furnishing } \\
\text { complements }\end{array}$ & $\begin{array}{c}\text { Brief launch } \\
\text { with the } \\
\text { company CEO }\end{array}$ & $\begin{array}{c}\text { Moodboard and } \\
\text { concept set up }\end{array}$ & $\begin{array}{c}\text { Concept } \\
\text { development }\end{array}$ \\
\hline $\begin{array}{c}\text { Fashion } \\
\text { Design }\end{array}$ & $\begin{array}{c}\text { Urban } \\
\text { clothing }\end{array}$ & $\begin{array}{c}\text { Brief launch } \\
\text { with the } \\
\text { company CEO }\end{array}$ & $\begin{array}{c}\text { Moodboard and } \\
\text { concept } \\
\text { development }\end{array}$ & $\begin{array}{c}\text { Final design and } \\
\text { outfit } \\
\text { development }\end{array}$ \\
\hline \hline
\end{tabular}

In the last phase of the activity, participants illustrated throughout oral and digital presentations the obtained results to the Samsara CEO. Fashion designers showed also the outfits they made. Qualitative interviews were then used to collect participants information about participants experience. Designers from both design fields were asked to answer some questions relating the design approach they conducted during the workshop period, in order to compare differences and similarities in the design processes.

\subsection{Steps of creation}

As the brief assignment was diversified in accordance with the design section, also the design method application in output development was different. To better understand how product and fashion designers conducted the creation process, the steps of creation were analysed for each of the two design field.

\subsubsection{Product Design working phases}

As a pre-established context of use was provided by the company, the intensive workshop period was set up as an experimental phase relating the design methodology application, starting from the concept definition and development. For Product Design section each activity of the educational experience is described.

Preliminary activity - Participants started studying Dreamlux fabric throughout material provided by the company, as Dreamlux informative material and samples, which allowed participants to experiencing it in first-hand. These tools led to the creation of moodboard for inspiring ideas and to subsequent concepts set up, which consisted in preliminary sketches and design proposals production.

Full immersion period - In this phase, participants had to concentrate in concept development. An indepth analysis of material's technical characteristics has been conducted in order to resolve the problematic issues that were identified during preliminary concepts set up phase. 3D modeling and renderings development followed the concept engineering process till the production of technical drawings.

The construction of a prototype was not included in workshop activities, as production processes and factors as time and tools provided by the workshop organization made it unthinkable to obtain.

\subsubsection{Fashion Design working phases}

Fashion Design section aimed, on the contrary, to the creation of the physical outfit. For this reason, participants started in concept development the day after the brief was launched. The context of use was been pre-established as was done for the Product Design section and the workshop activities followed the described structure.

Preliminary activity - Fashion designers studied the material under the same conditions as those provided for product designers, and produced moodboard and conceptboard. Thus, they began to develop croquis and technical drawings, reviewing the progression of the work through a series of established review sections with the teaching section. 
Full immersion period - Preliminary activities allowed participants to have the material required for the final design and outfit development phases. Fashion designers had to produce paper models in order to create the physical outfit. The company provided them the required Dreamlux material that has been applied in clothing products.

\subsection{Interviews}

Qualitative interviewing is a flexible and powerful tool to capture the voices and the ways people make meaning of their experiences [10]. For this reason, at the end of the educational experience participants were asked to answer some questions in order to understand the qualitative results relating the workshop. Questions were the same for all respondents and concerned the applied criteria in design process both from an overall point of view and from a more specific one relating the educational experience conducted. Moreover, participants were asked to describe positive and negative aspects relating the full immersion approach for the project development compared to the traditional academic PBL, and the advantages in CEO company support. One of the most significative interview for each design section have been reported in the following paragraph.

\section{RESULTS}

At the end of the activity, all participants final works have been collected, and consideration relating the design approach applied and critical issues identified during the workshop have been registered through interviews. In the following paragraphs two selected output, respectively from Product and Fashion Design section, have been showed and discussed. Afterwards, qualitative interviews for each design field have been reported.

\subsection{Product Design section}

Product designers rarely had to handle a textile material in academical context, unless for decorative purposes. In general, materials' classes at Politecnico di Milano include in-depth information on industrial traditional materials and manufacturing processes, where three-dimensional characteristics provide basis for the project development. Thus, the main critical issue in creating a Dreamlux application in a product design context has been that to find a different role, rather than a cover, for a two-dimensional material. To understand how the material could be cut maintaining fibers brightening as well as shaped and integrated into a product, have been additional critical aspects for product designers. Nevertheless, they have found less difficulties in resolving technical issues, as they were topics more inherent to the design education received during university period. Set out below is the detailed description of one of the concept developed by participants during the educational experience.

\subsubsection{Dreamlux as a pouf}

Starting from the inspirational moodboard, "Pouf" was one of the concept that has been developed during the educational experience. The concept consisted in a seat in which the Dreamlux fabric has become integrant part of the product, as it was braided with another material to create the external structure of the seat. The inspirational moodboard aimed to reach the connection with braided patterns and with objects in which materials are both the supporting structure and the aesthetical component. During the concept phase, cutting the material in the correct way and analyzing the alternatives in positioning cabling and batteries components, they started to develop the "Pouf" seat (Fig.2). Figures show the phases of creation until the concept development was ended. Fig. 3 represents the 3D renderings of the product, including the assembly steps of the seat. A tubular metal frame represents the main structural support of the seat. Around the rounded base and the seat-place rounded tubulars, a series of bands of Dreamlux fabric have been wrapped around in vertical direction. Similar proceeding has been applied to assemble the nylon bands, which wrapped in the main rounded tubulars in order to guarantee an adequate loads support when user is seated. "Pouf" assembly carried on through alternating in an horizontal and consequential configuration the Dreamlux and nylon bands. Thus, Dreamlux fiber is an integral component of the product, and enriches through its brightening characteristics the final aesthetic component of the seat. Fig. 4 shows "Pouf" 3D renderings in its daylight and at night hypothetical environments. Technical drawings were produced at the end of the concept development, as basis for a future product development and prototype building. 
pouf - seat

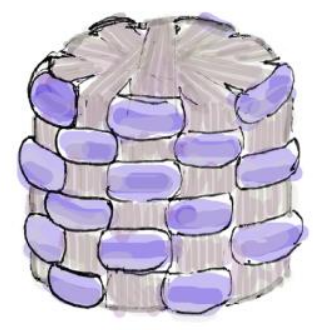

tubolar metal frame:

oad-bearing structure

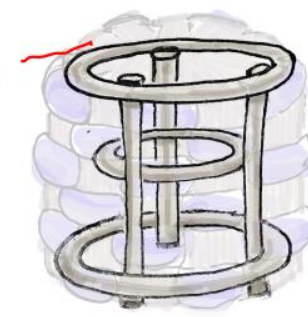

\section{DETAILS}
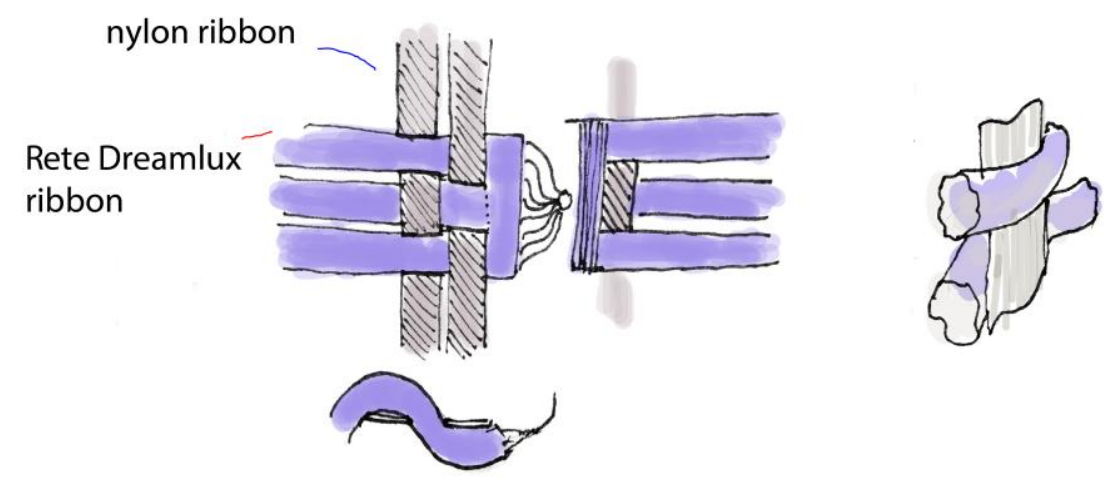

Fig 2. "Pouf" preliminary conceptboard made by sketches and functional details

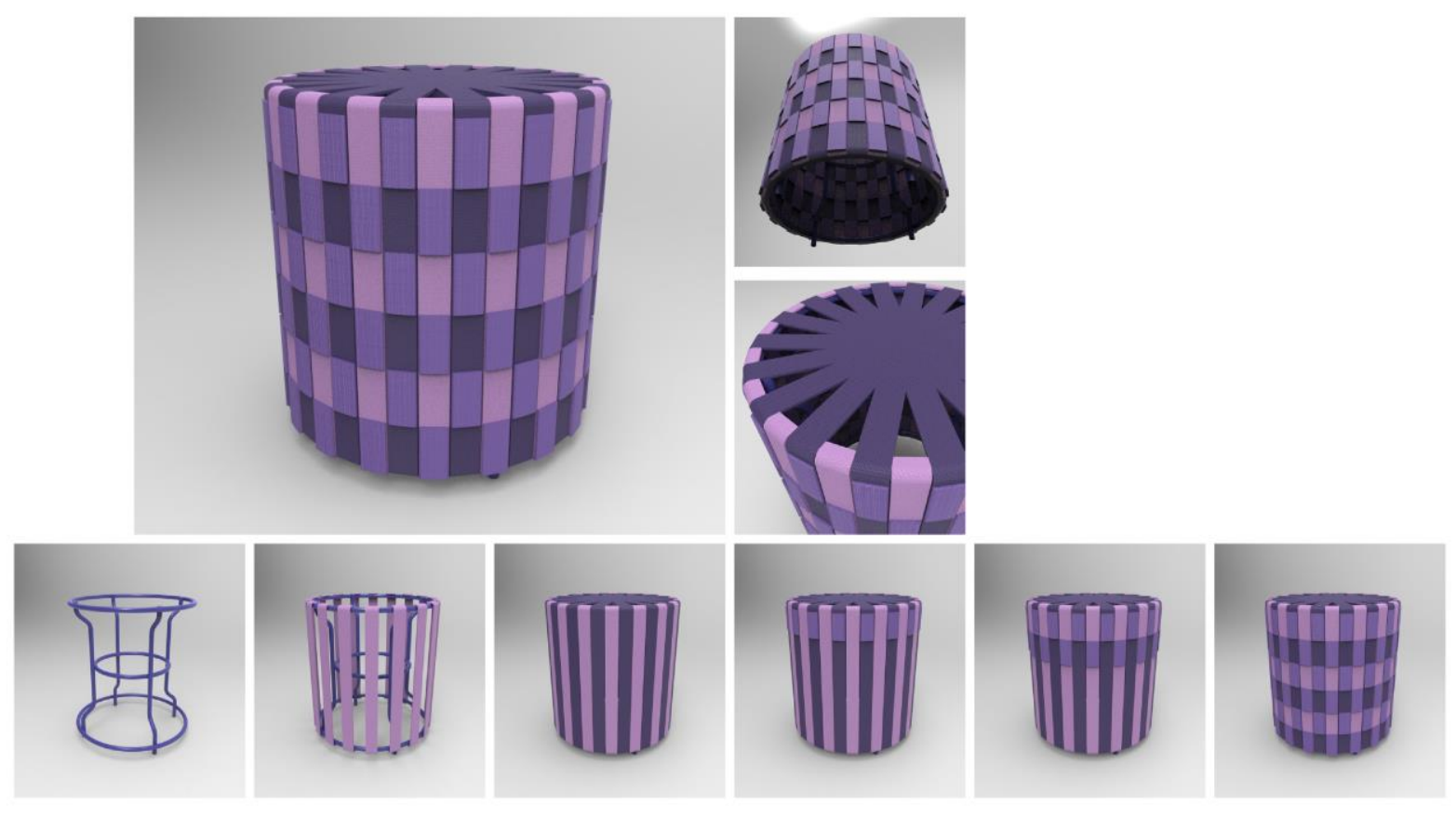

Fig 3. 3D renderings of the product and assembly steps of the seat 

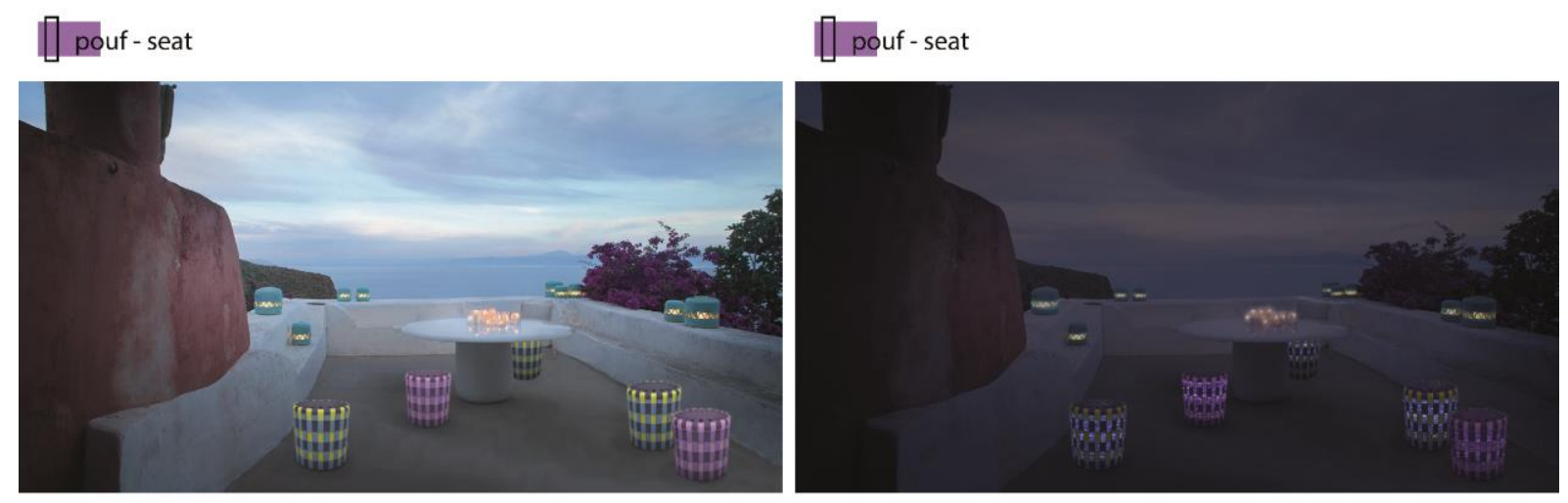

Fig 4. "Pouf" $3 D$ rendering in its daylight (left picture) and at night (right picture) hypothetical environments

\subsection{Fashion Design section}

As fashion designers, participants were used to handling textile materials. Nevertheless, to develop an outfit through an unconventional fabric enabled participants to think differently and to experience difficulties in set up the project without underestimating Dreamlux technological components. Thus, fashion designers had to pay more attention in optical fibers sewing proceeding and in cabling and batteries positioning in order to keeping the outfit comfortable.

One of the outfit development proceeding is described below.

\subsubsection{Light in the dark, an urban coat}

According to the pre-established brief, the urban context was the main constraint of the project. Thus, the research started with considerations of many nature in order to explore and select the more appropriate idea for the concept set up. Fashion designers frequently are used to create their outfit throughout similarity and abstraction processes from real-world scenarios. In accordance with this principle the through which fashion system produces meanings, values and identities, the concept "Light in the dark" has been developed starting from the reinterpretation of notions which belongs to the urban reality through the use of keywords, such as "lightness, darkness, geometry, essentiality, and layers".

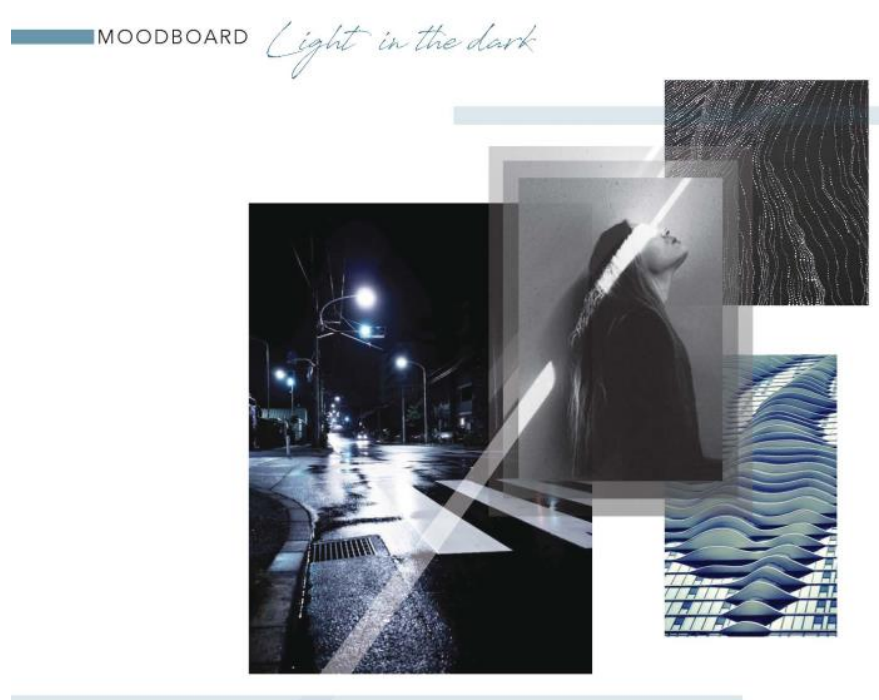

Fig 5. "Light in the dark" coat moadboard 
The moodboard (Fig. 5) and the conceptboard show the results related to the pre-design process. Concept was set up and developed through the croquis (Fig. 6) and technical drawings. The "Light in the dark" coat aimed the walking street to be illuminated despite the darkness of the night. Thus, the internal side of the coat had been covered with Dreamlux in order to permit the light come out when fibers are brightening. However, in "Light in the dark" coat the Dreamlux fabric was visible also from the outside, as laser cutting process has been applied to the traditional textile material through which the article was made up. After concept development was concluded, the paper model was created and then the outfit was sewn (Fig. 7).

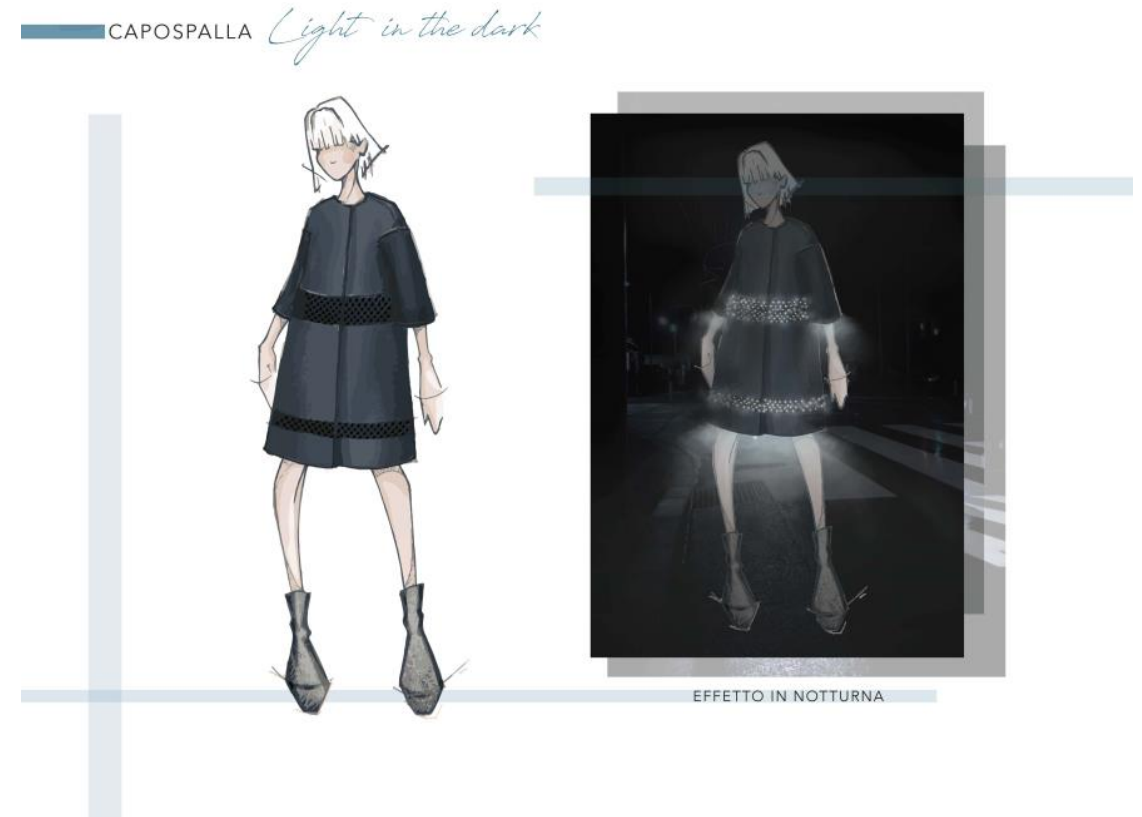

Fig 6. Croquis representative of the concept

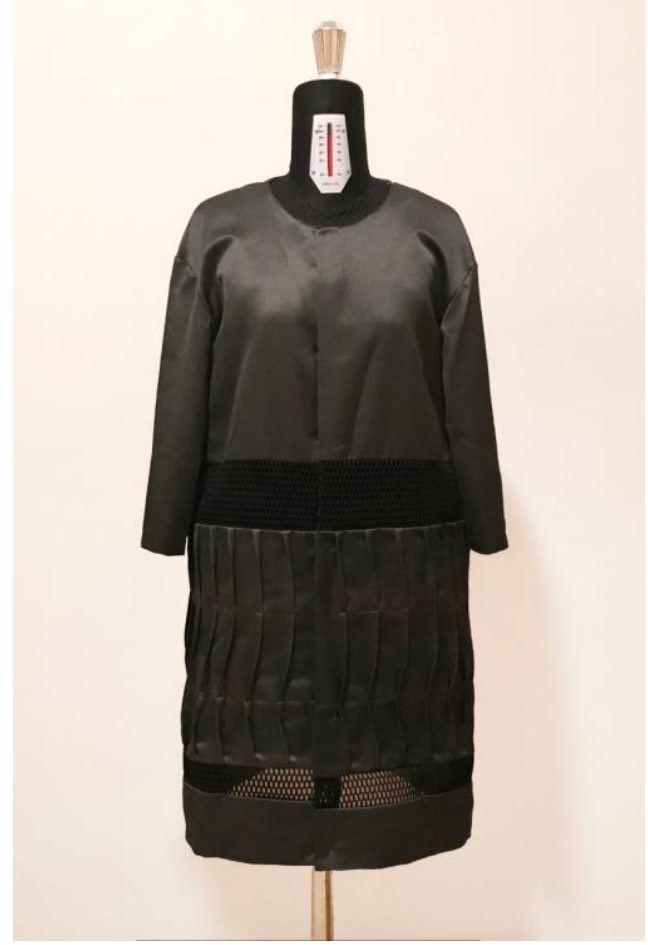

Fig 7. "Light in the dark" final outfit 


\subsection{Understand the results, participant interviews}

The answers given by product and fashion designer during interviews revealed personal design approach in project development and some considerations about the educational experience. Questions were the same for product and fashion design participants apart Q2 one, which was not asked the second ones, as fashion designers are used to work with two-dimensional materials. The cited interview reports the most meaningful answers obtained by "product designer" (PD) and "fashion designer" (FD) as following:

Q1 - Which aspects of a design project do you further aim to focus on?

PD - "The first step during design process is to trying to identify what the primary and secondary characteristics of the material I want to use are. It is very important that the material does not diminish the final product, but rather, enhances it. Then I try to accentuate the material potentialities finding new product mode of uses in order to surprise both the designer and the end user."

FD - "Creating a new product is always a challenge to face at the best. When I think about a new project I like to try to understand how to enhance the material. I'm not a lover of prints, thus I usually try an outfit to be unique through the fabrics that I use, and to create, thanks to the volumes, an interesting and original product, which can quickly capture the attention of the final consumer."

Q2 - Which difficulties did you most find while designing with a two-dimensional material as a textile?

PD - "As a product designer, I have never studied the physical characteristics and manufacturing processes of a textile material."

FD - Question not asked

Q3 - Which difficulties did you most find while designing with Dreamlux material?

PD - "It was difficult to find a different usage than the exclusively decorative one, and to understand how to handle and cut the cabling in order to produce a correct concept development"

FD - "When I had the opportunity to work with a completely new fabric for me, I must admit that I was initially a bit scared. However, I did not let myself down and I tried to create something different while remaining within the prêt-à-porter context. The first approach with the sewing machine and Dreamlux was quite complicated, as I was afraid of cutting the fabric incorrectly during marker making, but I must say that once I passed this critical steps, I could work with Dreamlux fabric easily."

Q4 - Which positive aspects did you find in designing in a short-time period experience compared with the traditional academic $P B L$ ?

PD - "Working for a short time period on the same project has helped me to keep very focused on the work I was developing. Moreover, to have a short time available has encouraged a continuous exchange of opinions between me and other participants, making me feel in a real creative environment."

FD - "Working over a short period of time has allowed me to be completely concentrated into the concept development. From the outset I had clear the idea of the outfit I wanted to accomplish and my research was more targeted and more effective."

Q5 - Which negative aspects did you find relating Q4?

PD - "First I wanted to analyze issues about textile materials more in-depth. I would also like to have the chance to build the prototype of the proposed concept."

FD - "If I had had more time I wanted to create other items to match with my product and develop a fashion line or create color variations. I am satisfied with the final outfit I obtained and I believe that, in its original simplicity, it is able to emphasize Dreamlux fabric."

Q6 - Was the CEO company support useful for your work?

PD - "Yes it was since the professionality through which he commented my work has been very precious for me. Nevertheless I would like to receive more feed-backs during the concept development instead of just a final comment."

FD - "Yes it was, as I could receive a fast and concrete feed-back relating my project instead of academical evaluations" 


\section{CONCLUSIONS}

The PBL approach adopted in the short-time educational experience proves to be an effective solution to get participants a prospective on the properties of the textile material they use, and to learn which possibilities are given by it. The involvement of an industrial company into the workshop has been useful as it gave designers precious feed-backs from an industrial point of view. Despite the brief assignment was diversified in accordance with the design section, it is possible to compare the design process applied by product and fashion designer in order to understand their different approaches and considerations in design methods for product development. Qualitative interviews allow to better understand how participants from different academical background lived the educational experience and how to find differences in design approach when an innovative material is provided for a new project development. Technical characteristics of Dreamlux have been a common difficult aspect for both product and fashion designers in project development. Nevertheless, the first one declared to have found more critical issues in material role interpretation, while the second one in processing it in order to create the final outfit. If product designers revealed an approach focused on the knowledge of manufacturing and technical properties of the material before starting with the concept set-up, fashion designers produce meanings, values and identities through similarity and abstraction processes of real-world scenarios.

\section{REFERENCES}

[1] E. Karana, O. Pedgley, and V. Rognoli, "On Materials Experience," Designlssues, vol. 31, 2015.

[2] P. Antonelli, Mutant Materials in Contemporary Design. 1995.

[3] B. Del Curto and M. P. Pedeferri, "A new educational approach in design faculty for teaching materials science," EDULEARN10 Proc., pp. 114-121, 2010.

[4] C. L. Dym, A. M. Agogino, O. Eris, D. D. Frey, and L. J. Leifer, "Engineering Design Thinking, Teaching, and Learning," J. Eng. Educ., 2005.

[5] A. J. Dutson, R. H. Todd, S. P. Magleby, and C. D. Sorensen, "A Review of Literature on Teaching Design Through Project-Oriented Capstone Courses,” J. Eng. Educ., 1997.

[6] P. D'Olivo, B. Del Curto, J. Faucheu, D. Lafon, J.-F. Bassereau, and D. Delafosse, "Education and research: when design and engineering perform new links with the industrial world," INTED2013 Proc., 2013.

[7] E. Manzini, The Material of Invention. 1986.

[8] E. B.-N. Sanders and P. J. Stappers, "Co-creation and the new landscape of design," CoDesign, vol. 4, pp. 5-18, 2008.

[9] M. Givoletti, "Textile product with illuminated fibres, article made therefrom and production method of the same," 2000.

[10] S. E. Rabionet, "How I Learned to Design and Conduct Semi-structured Interviews: An Ongoing and Continuous Journey," The Qualitative Report, pp. 203-206, 2009. 